\title{
Germán Greve Schlegel y la recepción del psicoanálisis en Chile: la historia de un médico chileno "probablemente alemán"*
}

Germán Greve Schlegel and Reception of Psychoanalysis in Chile: The Story of a "Probably German" Chilean Physician

Recibido: enero 21 de 2014 | Revisado: abril 9 de 2014 | Aceptado: julio 17 de 2014

\author{
MARIANO RUPERTHUZ HONORATO ** \\ Universidad de Santiago de Chile, Chile
}

doi:10.11144/Javeriana.upsy13-5.ggsr

Para citar este artículo: Ruperthuz, M. (2014). Germán Greve Schlegel y la recepción del psicoanálisis en Chile: la historia de un médico chileno "probablemente alemán”. Universitas Psychologica, 13(5), 1847-1867. http://dx.doi.org/10.11144/Javeriana. upsy13-5.ggsr

El presente trabajo es una porción de mi investigación doctoral titulada "Freud y los chilenos: historia de la recepción del psicoanálisis y Chile (1910-1949), bajo la dirección del Dr. Roberto Aceituno y el Dr. Mariano Ben Plotkin. Doctorado en Psicología, Universidad de Chile.

** Contacto principal para correspondencia editorial. Correo electrónico: mruperthuz@ug.uchile.cl

\section{RESUMEN}

El presente trabajo amplía los antecedentes históricos de una de las primeras referencias sobre el psicoanálisis en Latinoamérica: la exposición del médico chileno Germán Greve Schlegel en Buenos Aires en 1910. Se constata, basado en fuentes históricas primarias, cómo Greve habría tomado contacto con el freudismo desde finales del siglo XIX, describiendo el marco específico de ese encuentro y se analizan detalles sobre la participación de este médico chileno en la escena médica. Se trabaja desde el marco referencial y metodológico que piensan al psicoanálisis como un sistema de ideas y creencias de carácter transnacional, cuya recepción en cualquier espacio local implica un proceso activo de lectura, reinterpretación y adaptación a las distintas realidades en las que se inserta.

Palabras clave

historia; psicoanálisis; Chile; círculo médico; Germán Greve Schlegel

\section{A B S T R A C T}

The present article extends the historical precedents of one of the first references on the psychoanalysis in Latin America: the dissertation of the Chilean doctor Germán Greve Schlegel in Buenos Aires in 1910. It is verified, based on historical primary sources, how Greve would have taken contact with the Freudism from ends of the 19th century, describing the specific frame of this meeting and details are analyzed on the participation of this doctor in the medical Chilean scene. This work defines to the psychoanalysis as a system of ideas and beliefs of transnational character, which reception in any local space involves an active process of reading, reintepretation and adjustment to the different realities those who are inserted.

Keywords

history; psychoanalysis; Chile; medical circle; Germán Greve Schlegel 


\section{Introducción}

\section{Germán Greve Schlegel y su lugar en la historia del psicoanálisis: perspectivas de un problema de investigación}

Una de las primeras referencias registradas sobre psicoanálisis en Latinoamérica fue la exposición del médico chileno Germán Greve Schlegel en Buenos Aires en 1910. Si bien Greve, después de eso, no tuvo una participación mayor en el campo psicoanalítico-de hecho fue el único trabajo que le dedicó al tema-su caso es una oportunidad interesante para conocer varios de los antecedentes sobre el proceso de recepción del pensamiento freudiano en Chile y la región. De esta forma, un trabajo como el que intento proponer ayudaría a abordar un tema pendiente que Rubén Ardila (1998) ya había advertido con anterioridad. El investigador colombiano, refiriéndose a la historia del psicoanálisis en Chile, afirmó que:

Una de las figuras pioneras del movimiento psicoanalítico en Sudamérica fue el médico chileno Germán Greve, quien defendió en el Congreso Médico Internacional de Buenos Aires una monografía titulada "Sobre psicología y psicoterapia de ciertos estados angustiosos" [...]. En dicho trabajo preconizó la existencia de la sexualidad infantil; la tesis fue evaluada positivamente por Freud. [...] Germán Greve fue principalmente una figura aislada de la que se conoce muy poco ${ }^{1}$. (pp. 169-170)

Tal como lo indica Ardila, la inmortalidad de Greve en el campo psicoanalítico estuvo garantizada por las dos reseñas que Sigmund Freud hizo sobre su exposición. Sin embargo, hasta la fecha no existen informes que entreguen mayores antecedentes sobre él o que, específicamente, ayuden a comprender cómo este médico chileno tomó contacto con el psicoanálisis, cómo lo practicó clínicamente y de qué modo intentó presentarlo a sus colegas (tanto chilenos como extranjeros).

1 Las cursivas son mías.
Bajo este marco, el presente trabajo es una porción de una investigación mayor sobre la historia de la recepción de las ideas psicoanalíticas en Chile durante las primeras cuatro décadas del siglo XX (Ruperthuz, 2013), que considera al trabajo de Germán Greve como un primer hito para acceder a la investigación de un complejo proceso como es la recepción de un sistemas de ideas y creencias transnacional como el psicoanálisis. Puedo afirmar que la historia del psicoanálisis en Chile, hasta ahora, ha sido un campo de estudio descuidado por los investigadores, quienes se han centrado preferentemente en la historia institucional del psicoanálisis, entendiéndola como el momento de instalación de una práctica clínica canónica, sintetizada en la fundación de una "sociedad oficial", la Asociación Psicoanalítica Chilena (APCH) filial de la Asociación Internacional de Psicoanálisis (IPA), en el año 1949.

Estas referencias comparten algunas características: se identifican por ser estudios breves, generalmente onomásticos y univariables en el análisis histórico, privilegiando un costado preferentemente institucional (Arrué, 1990; Casaula, Coloma, \& Jordan, 1991; Davanzo, 1993; Núñez, 1981; Witing, 1980). La fundación de la sociedad local es vista como el "momento cero" de la línea del tiempo desde donde se empieza a escribir la historia "oficial" del psicoanálisis en Chile. Lo anterior a esto será, por lo tanto, prehistórico y los personajes influyentes de ese periodo recibirán el adjetivo de difusores o pioneros (que lo fueron) en contraposición con aquellos formados "oficialmente", mostrando como la institución psicoanalítica le da legitimidad a sus protagonistas. En este mismos sentido Hugo Vezzetti, historiador del psicoanálisis y la psicología en Argentina, ya había mostrado cómo en los estudios del psicoanálisis en la Argentina también enfatizaban el carácter inaugural y novedoso de la fundación de la Asociación Psicoanalítica Argentina (APA) en el año 1942, descuidando las condiciones previas a su nacimiento (Vezzetti, 1996).

Sin embargo, esta condición no es exclusiva del psicoanálisis nacional o regional, ya que, como lo afirma Mariano Plotkin (2003), dentro del campo de investigaciones que intentan abordar la historia 
del psicoanálisis en términos generales existirían al menos tres "modos" o "estilos" bien definidos de encarar y pensar su historia, generando verdaderas tendencias historiográficas perfectamente distinguibles, las que conviven hasta ahora de manera sincrónica en el campo historiográfico psicoanalítico:

a) Los trabajos centrados en la figura de Freud como único autor y creador del psicoanálisis. En este grupo de abordajes -dentro de los que se cuentan los trabajos del mismo Sigmund Freud (1914), Ernest Jones (1970), Peter Gay (1996) y Louis Breger (2001), entre otros- donde Freud es representado como un verdadero héroe solitario, cuyos descubrimientos no reconocen casi ninguna genealogía intelectual y la teoría freudiana sería una especie de creación ex nihilo. Para ser más concreto, esta corriente historiográfica se inauguraría con el trabajo de Freud Contribución a la historia del movimiento psicoanalítico (1914/1972), donde el psicoanálisis coincide con la historia personal de su autor.

b) Más tarde, nuevas investigaciones comprendieron que el nacimiento psicoanálisis tuvo directa relación con su entorno más próximo, dando paso a los abordajes históricos denominados contextualistas. Así, las investigaciones de autores insignes como Henri F. Ellenberger (1970), Carl Schorkse (1979) y William J. McGrath (1986) entre los más representativos, analizaron cómo las vicisitudes compuestas por las condiciones sociales, políticas y económicas de la Viena de fin-de-siècle moldearon el nacimiento del psicoanálisis. Entre ellas se puede contar, por ejemplo, el declive del sistema liberal vienés y la correspondiente reorganización del papel que los judíos ocuparían en dicha sociedad vienesa, lo mismo que la evolución de las teorías psicodinámicas en el campo médico-psiquiátrico (tomando en consideración los trabajos de autores como Charcot, Janet, Freud, Jung y Adler, entre otros) y su directa relación en la génesis del psicoanálisis.

c) Por otro lado, en los últimos años se ha abierto una nueva corriente de investigación -de la cual este trabajo intenta ser parte-, sobre la historia del psicoanálisis: los estudios que se preocupan por la circulación transnacional y la apropiación de las ideas freudianas en ciertos espacios socioculturales deter- minados (Plotkin \& Damousi, 2009). Esta mirada entiende al psicoanálisis como un cúmulo de ideas y creencias que tiene la propiedad de transitar por distintos espacios nacionales y culturales, siendo recepcionado y utilizado de distintas formas, llegando inclusive a empapar varias capas de la sociedad en la que es recibido. El proceso de recepción es un fenómeno activo de parte de los agentes locales y destaca las distintas reapropiaciones y reinterpretaciones que ellos hicieron de las ideas de Freud, haciéndolas compatibles con varias de las tradiciones de pensamiento que dominaban la escena local (Dagfal, 2004; Plotkin, 2003; Vezzetti 1996). Esta posición ayuda a apartar la supuesta idea de la existencia, en términos históricos, de cierta manera "correcta" de leer y aplicar los conceptos del psicoanálisis.

A partir de estos antecedentes, adhiero a la necesidad de utilizar una nueva definición de psicoanálisis, la que considero indispensable para cubrir los distintos frentes que lo comprenden como un objeto cultural amplio, permitiendo con ello visualizar en el tiempo la génesis de distintas prácticas y discursos que se legitimaron en una (real o supuesta) genealogía freudiana (Makari, 2008; Plotkin, 2003).

La historia de la llegada del psicoanálisis a Chile, representada en estos términos, ayudaría a observar el episodio protagonizado por Germán Greve Schlegel como parte de un proceso más amplio y deja de pensarlo como un hecho aislado, ayudando, además, a dilucidar los distintos canales y medios utilizados para el aterrizaje del freudismo al país, pensando en la existencia de distintas formas de "transmisión", tales como diversas publicaciones, personas y cartas, entre otros, a las que el chileno pudo haber tomado contacto (Briggs \& Burke, 2007).

De esta forma, me alejo de los abordajes tradicionales sobre la historia del psicoanálisis que utilizan conceptos como "psicoanálisis verdadero" o "psicoanálisis oficial", resguardando celosamente lo que merece ser calificado como "psicoanalítico" o "freudiano", poniendo la mirada en lo que los actores locales entendieron por psicoanálisis y qué hicieron con él. Tengo claro, por lo tanto, que quedarse en este nivel es continuar historizando 
solo las referencias acerca de "analistas, pacientes, teorías psicoanalíticas y asociaciones profesionales" (Plotkin, 2003, p. 14), lo que implicaría investigar históricamente exclusivamente lo que ocurrió con el devenir del movimiento psicoanalítico. Esta lógica está presente en el libro Cuarenta años de psicoanálisis en Chile (1991) -hasta ahora la obra más extensa que busca hacer una recapitulación histórica del psicoanálisis a nivel local- donde sus autores, preparando a los lectores sobre la materia de la que tratará la primera sección de la obra, afirman:

La PRIMERA PARTE está dedicada a los pioneros y a los fundadores del psicoanálisis en Chile. No resulta fácil una caracterización dado que no todos los mencionados se formaron oficialmente, sin embargo su trayectoria resulta inestimable para la consolidación de la Sociedad Psicoanalítica en 1949. Destacamos aquellos que han mantenido su adhesión a lo psicoanalítico en forma sostenida, sin constituir disidencias. (Casaula et al., 1991, p. 21)².

Si volvemos sobre el caso de Germán Greve, desde esta perspectiva no lograría ser calificado como un "psicoanalista oficial" y a lo más se lo podría denominar un "psicoanalista silvestre" (Freud, 1910) ${ }^{3}$.

\section{Metodología}

Una investigación histórica sobre el psicoanálisis, centrada en la participación de Germán Greve Schlegel, no puede ser separada de las condiciones específicas que envolvieron y contextualizaron su encuentro con el freudismo. Por lo tanto, aproximarse a la historia de la recepción del psicoanálisis es sinónimo de estudiar una porción de la historia social, política, intelectual y científica de Chile. Sigo en esto a Aróstegui, quien define a la investigación histórica como aquellos trabajos "que tienen como objeto el comportamiento de las relaciones sociales en función de sus movimientos temporales (recurrentes o transformadores)" (Aróstegui, 2003, p. 150). Se

2 Las cursivas son mías.

3 Un ejemplo de este tipo de consideraciones es el artículo de Arrieta y Gomberoff (2007). subentiende, entonces, que la llegada de las ideas freudianas a Chile impactó y autorizó la producción innovadora de discursos y prácticas que pueden ser detectadas y analizadas (Estado social primero Acontecimiento [llegada del psicoanálisis] - Nuevo estado social). El levantamiento de información de las fuentes de históricas, más la aplicación del método historiográfico, definido como aquellos pasos necesarios para poder reconstruir cierto fenómeno o fenómenos sociales a partir de la elaboración de ciertas hipótesis de trabajo, permitirá que los datos encontrados puedan elaborarse para producir un relato histórico lo suficientemente argumentado que dé cuenta de la particularidad, en este caso, de la recepción del psicoanálisis en Chile (Aróstegui, 2003). Por último, el presente trabajo correspondería a lo que este mismo autor define como un estudio sectorial, en sus dos dimensiones, ya que aborda la historia de una temática específica (el psicoanálisis) en un espacio territorial específico (Chile) y en una época temporal determinada (1910).

En términos metodológicos, tendré en cuenta lo planteado por el investigador chileno Eduardo Devés-Valdés a través de su noción de "ruta intelectual"4, quien se pregunta

¿Por qué interesa la circulación de las ideas? Porque se trata de un problema, tal como interesa la circulación de personas, de los bienes o del dinero. Pero, también como estos, la circulación de las ideas es un asunto que se conecta con muchos otros como son, por citar algunos: la dependencia cultural, las modas intelectuales y los impactos de unas sociedades sobre otras. [...] producción del conocimiento y circulación del conocimiento (o de las ideas) son dos asuntos interconectados y esta interconexión adquiere mayor relevancia cuando la producción de conocimiento se concibe como un proceso no sólo espontáneo de algunas mentes brillantes (al modo antigua artesanal), sino como un quehacer programado de vastas comunidades intelectuales (al modo moderno industrial). (Devés, 2008, p. 87)

4 Dentro de los trabajos a los que he podido tener acceso, recomiendo: Eduardo Devés (2007, 2008, 2009), cuyas referencias se encuentran al final del presente escrito. 
Así, la interconexión por donde se transmite el conocimiento recibe el nombre de ruta intelectual, reuniendo a un conjunto de personas ocupadas en la producción y difusión del conocimiento, las que establecen puentes de comunicación perfectamente detectables. Estas rutas tienen la función de ser las vías por las cuales se transportan las ideas, pudiéndose discriminar su densidad y profesionalización. Para Devés existiría una metodología que permitiría dilucidar las formas de comunicación involucradas en una red intelectual. Vale decir: a) cara a cara, b) correspondencia, c) participación en los mismos congresos, sociedades, agrupaciones, d) prologación, comentario o presentación de libros, e) publicación en los mismos medios, f) participación en las mismas campañas o iniciativas, g) diálogos, polémicas, h) citaciones recíprocas e i) otros contactos posibles (Devés, 2007).

El aporte de esta noción es interesante para pensar el caso de Germán Greve ya que es el que permitiría conformar verdaderas cartografías intelectuales, evidenciando cómo circulan las ideas en un espacio-tiempo determinado. Además, entrega importante información sobre los contactos profesionales o personales que cualquier miembro de la red estableció, ocupándose, al mismo tiempo, de las hibridaciones y evoluciones en los ecosistemas intelectuales de los cuales son componentes. También permiten trabajar sobre la noción de influencia de ciertas ideas en un contexto determinado, alejando las nociones "robinsonescas" de un autor solitario que pudiese producir un trabajo intelectual. Por último, el concepto de la red intelectual permite complementar las nociones de "generación del conocimiento", poniendo énfasis en la colaboración entre agentes, y "campo intelectual" -tal como lo plantea Bourdieau- en las cuales se lucha por conseguir el capital simbólico en juego (Devés, 2007).

\section{Periodización y supuestos}

Tengo en cuenta que cualquier periodización es más bien tentativa y referencial. Sin embargo, su formulación se hace necesaria para considerar ciertos márgenes temporales en los cuales se enmarque la búsqueda, que, por supuesto, serán móviles y definitorios solo al final de la investigación. Por ello -y apoyándome en lo referido anteriormente- el hito de la participación de Greve en Buenos Aires en 1910 para indagar antecedentes de esa contribución, tratando de hacer emerger los circuitos de recepción de los que este médico nacional participó, lo que potencialmente haría móvil el espacio de tiempo que será explorado para dar cuenta de la historia de Germán Greve.

Por otro lado, los supuestos que sustentan el presente trabajo son:

a) La oferta tradicional en términos historiográficos sobre psicoanálisis en Chile, hasta el momento, invisibiliza los aportes que varios agentes locales hicieron al momento de participar en los circuitos de recepción del pensamiento freudiano en el país. Dichos aportes se que los considera como capítulos previos de la historia oficial de la disciplina, contada desde una perspectiva exclusivamente institucional. Esto se puede evidenciar en las consideraciones que hacen referencia a Greve.

b) Estos aportes pueden ser recuperados nuevamente para evaluar su significación, a través de una búsqueda reorientada que tenga en cuenta los beneficios de pensar al psicoanálisis de manera más amplia: definido como un sistema de ideas y creencias transnacional, íntimamente relacionado con las condiciones locales de producción intelectual y siendo parte de corredores de transporte de ideas, los que conectan centros de producción y consumo de saberes especializados.

\section{Fuentes}

Las fuentes son aquellos documentos, obras o materiales que sirven para obtener información del fenómeno estudiado, siendo, como dice su nombre, la fuente de donde se alimentará la investigación (Dussaillant, 2006). Las fuentes serán consultadas, evaluadas, organizadas e interpretadas, permitiendo aplicar los elementos propios que la historiografía establece para este tipo de investigación.

Se contempla el uso simultáneo de fuentes y documentación primaria y secundaria. Entendiendo las primarias como aquellos materiales 
escritos (textos, cartas, diarios, informes, estudios, memorias, documentos oficiales, diarios de viaje o de vida, etc. que tengan relación con el tema), imágenes y sonido (registro fotográficos, fonéticos, grabaciones de todo tipo y fuentes iconográficas como pinturas u otras) u objetos (cualquier objeto relacionado directamente con el tema puede ser una fuente) producidos por las personas o grupos directamente involucrados en los eventos considerados en la investigación, como participantes o testigos (Kelleher, 2009). No se debe perder de vista que la significación de ese tipo de material solo puede ser entendido en su "contexto de producción".

Por otro lado, las fuentes secundarias son aquel material que refleja la acumulación de conocimiento, teorías y debate acerca de un tema específico sobre la historia del psicoanálisis en Chile (libros y artículos especializados que anteriormente ya hayan interpretado las fuentes primarias). La necesidad de consultar este tipo de fuentes radica en que permite detectar el debate actual en torno al trabajo de investigación.

Como el presente estudio se centra en la obra de Germán Greve en relación con la recepción del psicoanálisis en Chile, la búsqueda de fuentes se generó a partir de un rastreo múltiple, donde se revisaron, en el periodo de tiempo indicado (1910), las principales publicaciones médicas de la época, cuyas referencias bibliográficas guiaron hacia otras, ayudando a completar un cúmulo de fuentes documentales que tenían relación directa o indirecta con la obra de este médico chileno. Esta fase contribuyó a delimitar las fuentes pertinentes de análisis y medir su peso heurístico. Dentro de las fuentes primarias se encontraron (todas ellas consultadas en las distintas colecciones especializadas de la Biblioteca Nacional de Chile):

a) Revistas especializadas: Revista de Medicina, Revista de Psiquiatría y Disciplinas Conexas, Revista de Criminología y Ciencias Penales, Revista de Beneficencia Pública.

b) Actas de Congresos de medicina, psiquiatría, criminología y medicina social.

c) Archivos personales: principalmente el de la familia de Germán Greve Schlegel, que me entregó documentación de inestimable valor.
Por su parte, las fuentes secundarias dicen relación con aquellos trabajos que hacían referencia a la historia del psicoanálisis en la época y que consideran y analizan el aporte de Germán Greve.

\section{La medicina chilena de finales del siglo XIX: estado de alerta ante la degeneración y la necesidad de viajar para buscar nuevos conocimientos}

El mundo médico se estableció como puerta de entrada de las ideas de Freud a Chile. Hasta ahora, el primer indicio de la presencia del psicoanálisis puede detectarse muy temprano en el siglo XX, gracias a la ya mencionada exposición del doctor Germán Greve Schlegel titulada "Sobre psicología y psicoterapia de ciertos estados angustiosos" (Greve, 1910), leída en Buenos Aires, en el marco del Congreso Internacional Americano de Medicina e Higiene de $1910^{5}$. Hasta ahora, no se ha puesto atención en la estructura misma del trabajo, sus fuentes y la especificidad de la presentación que Greve hizo de Freud, elementos que entregan rica información sobre el patrón de recepción que los conceptos psicoanalíticos tuvieron en la época y que marcará buena parte del siglo XX. En otras palabras, la construcción argumentativa de Greve contiene unidades significativas que hablan del contexto de recepción y, especialmente, del clima de ideas que predominaban en la escena médica local que este médico intentará hacer coincidir con los postulados de Freud, logrando una presentación conciliadora. La influencia de la Escuela Francesa en la ambiente médico chileno-contingente con la amplia admiración por el mundo galo en la cultura de la época- hicieron que la operación de presentación y lectura de Freud, estuviera marcada por el deseo de que se asemejara lo más posible a figura del psicólogo Pierre Janet, quien, evidentemente, contaba con mayor prestigio e influencia para buena parte de los médicos chilenos y argentinos.

5 Particularmente, Chile y Argentina compartirán el mismo hito inaugural en sus respectivas historias locales del psicoanálisis (ver Plotkin, 2003). 
Los médicos locales siguieron fielmente los dictámenes y juicios, principalmente negativos, que sus pares franceses hicieron del psicoanálisis: se trataba de una teoría con un escaso sustrato científico, demasiado especulativa -más adecuada para el mundo literario que para la rigurosidad de la ciencia- y con un excesivo énfasis en el papel de la sexualidad como causa de los trastornos psíquicos, evidenciando lo terrenal y poco elevado de su inspiración germana (Roudinesco, 1986; Plotkin, 1996a; Plotkin, 1996b). La fidelidad al modelo francés generará, a mi modo de ver, una barrera a la internación e implantación más profunda de los conceptos psicoanalíticos en la incipiente escena psiquiátrica de la década del centenario chileno. Por ejemplo, el también médico chileno Fernando Allende Navarro, quien a mediados de la década de 1920 regresó de una larga estadía por Europa, donde se formó como psicoanalista en Suiza junto a Rorschach y Bleuler, palpó esa valla, siendo casi ignorado como psicoanalista, en comparación con su valoración como un experto neurólogo gracias a su trabajo con el célebre Constantin Von Monacow. El predominio del modelo anatomopatológico y el de la teoría de la degeneración como patrón explicativo-los que buscaban las lesiones cerebrales como causa de las enfermedades mentales, condimentado por un fuerte componente hereditario que predisponía al sujeto a la enfermedad-, restringirán significativamente las opciones para que la psicogénesis (más ligada a la biografía del enfermo) se presentara como una alternativa interpretativa.

Tal como lo refiere muy bien Rafael Huertas (1987), la teoría de la degeneración tuvo una pregnancia y repercusión importante no solo en el campo médico-psiquiátrico, sino que en casi todos los sectores de las sociedades modernas. Esta teoría, formulada por el francés August Morel en 1850, tuvo una rápida acogida entre sus pares como marco interpretativo de los graves problemas de la época. El degenerado poseía antecedentes familiares que justificaban su enfermedad -epilepsia, alcoholismo, enfermedades venéreas, prostitución y locura-, cuyos rasgos se hacían presentes en su cuerpo a través de estigmas bien definidos y reconocibles a los ojos del médico. En este caso, la forma de su cráneo, el tamaño de las cuencas de los ojos, la forma de sus orejas, entre otros, eran signos certeros de que estos sujetos poseían los resabios atávicos de la involución. El acento estaba puesto en el control y la reclusión de este tipo de sujetos, quienes eran vistos como una amenaza para la sociedad. Esta mirada alimentará mucho a la criminología, los discursos sobre las enfermedades mentales y la acción terapéutica de la medicina en función de una exclusión de los elementos peligrosos para el bien común. La transmisión hereditaria daba cuenta de estas malformaciones, por eso evitar la reproducción de estos seres debía ser una misión del Estado, guiada por el conocimiento médico. Este pesimismo biológico alimentaba verdaderas fantasías de catástrofe en las elites médicas y gobernantes, que se sentían amenazadas y con la misión patriótica de salvar al país de la desgracia.

En Chile, se pueden detectar varios antecedentes al respecto. En lo particular, quiero rescatar el discurso pronunciado por el doctor Augusto Orrego Luco, quien será el maestro de Germán Greve, y quien, al tomar posesión de su cargo de Presidente de la Sociedad Médica en 1895, hace un llamado a sus colegas a sostener fructíferas discusiones sobre el porvenir de la medicina, estar atentos a sus avances y ser unos artistas en términos sociales. En otras palabras, para él, los médicos debían hacer propaganda de la higiene a nivel social, ser reconocidos como agentes y promotores del cambio social a través de la difusión de sus descubrimientos. Pero Orrego Luco sabe que tiene limitaciones: "He dicho que hay en los dominios de la higiene un terreno cerrado para otros y abierto a nuestro estudio y propaganda. Me refiero, señores a ese implacable y sombrío imperio de las leyes de la herencia" (Orrego Luco, 1895, p. 54).

Esta era la barrera más inexpugnable que afectaba la acción médica, por lo que había que cambiar las estrategias de acción para ser efectivos. La sífilis, que afectaba a las mujeres contagiadas y mataba a los niños recién nacidos era un factor terrorífico para el futuro del país. Refuerza Orrego Luco:

iPues bien! en una de mis últimas lecciones, examinábamos en la clínica de enfermedades nerviosas dos 
enfermos, y en la historia del primero encontrábamos que había tenido 17 hermanos, todos muertos antes de nacer o en los primeros años de vida; y el segundo enfermo había tenido 22 hermanos, que habían sucumbido en la infancia víctimas todos ellos del mismo vicio hereditario. iQué estadísticas, qué horribles tablas mortuorias! (Orrego Luco, 1895, p. 54)

No hay escapatoria a la enfermedad mental y cada vez que se piensa en el futuro, el panorama es aciago y fatal. La medicina preventiva de Luco va por vulgarizar los conocimientos en la población, pero controlar también las infecciones posteriores las que hacen víctima a las nodrizas de esos niños. Los fantasmas de la Familia Yuke de Estados Unidos, con su descendencia de casi 200 criminales, que según Luco, era el ejemplo de la reproducción de la "embriología del crimen”. Este médico, que también tendrá un papel en política como diputado, alienta a sus colegas a que tengan una posición activa para sensibilizar al mundo público sobre los cambios que son necesarios en materia criminal y de salud pública. Sus fuentes principales son las obras del criminólogo Cesare Lombroso. Finalmente, Orrego Luco cierra su exposición con un tono pesimista que refleja el clima de la época:

Es triste, señores, que pudiendo marchar entre los pueblos más avanzados de la tierra, no hayamos ni siquiera sabido conservarnos al nivel de otros pueblos de América Latina. Es triste, señores, que estemos condenados a soportar las desesperantes dificultades de los pueblos nuevos y no tengamos, en cambio, esa facilidad para reformarnos, para modificar nuestras ideas, para avanzar en el camino del progreso, en que no estorban preocupaciones arraigadas, ni hábitos tradicionales nos detienen [...] Y así, las nuevas ideas que salen de la Vieja Europa, donde deban morir estériles, por falta, no de quién las crea, sino de quien las comprenda, irán a encontrar en el Nuevo Mundo quien las perpetúe fecundándolas y aplicándolas, [...] los grandes pensadores europeos recibirán nueva fuerza para sus trabajos y la última mirada de consuelo para una vida desconocida y burlada. (Orrego Luco, 1895, pp. 59-60)
Gracias a estos registros es posible comprender cómo un médico joven como Germán Greve Schlegel, de 24 años, tuvo el apoyo de Augusto Orrego Luco para viajar a Europa y actualizarse en materia médica. Los médicos chilenos ya habían acordado que su salida era mirar a Europa para buscar nuevas fuentes de inspiración teórica y práctica, para adaptarlas a sus necesidades y emergencias, y dar un nuevo aliento a la situación calamitosa del país. Teorías como las de Lombroso tuvieron el efecto de poner en alerta a las elites médicas y políticas, avivando sus estrategias de defensa social para salvar a la patria. Se verá, eso sí, cómo Greve no solo se encontrará con estos adelantos en tierras del Viejo Continente, sino además con una novedad: el psicoanálisis.

\section{German Greve Schlegel en Buenos Aires en 1910}

En el año 1971 el célebre paciente de Freud, de origen ruso, apodado 'El Hombre de los Lobos', publicó una serie de ensayos de carácter autobiográfico ${ }^{6}$. En uno de ellos, "Mis recuerdos de Sigmund Freud", deja ver su perspectiva sobre los alcances y el supuesto impacto del psicoanálisis a nivel mundial. Con tono restrictivo comenta: "Conocí a Freud en el año 1910. En ese tiempo el psicoanálisis y el nombre de su fundador eran prácticamente desconocidos más allá de los límites de Austria” (p. 135). Nada más alejado de la realidad, ya que si bien el mismo 'Hombre de los Lobos' había llegado a Freud luego de leer una obra suya en su Rusia natal, desconocía que las ideas de Freud circulaban en varias direcciones del planeta desde hacía mucho tiempo.

Coincidentemente, el mismo año en que este paciente se encontraba en el consultorio de Freud, un médico chileno, Germán Greve Schlegel (1869. 1954) de 41 años, viajaba a Buenos Aires a presentar los descubrimientos y su experiencia clínica con el psicoanálisis. Su viaje, en compañía de otros médicos chilenos, lo realizó en calidad de comisionado

6 El hombre original del 'Hombre de los Lobos' era Serguéi Konstantínovitch Pankéyev (1888-1976).

7 Traducción mía. 
del Gobierno de Chile y expuso su trabajo, titulado "Sobre psicología y psicoterapia de ciertos estados angustiosos" en el marco del Congreso Internacional Americano de Medicina e Higiene de 1910 (10 al 25 de julio de 1910) $)^{8}$. Greve participó en la sección de Neurología, Psiquiatría, Antropología y Medicina Legal de dicho certamen. Opino, como Plotkin (2003) ya lo decía, que la transcendencia del trabajo de Greve no vino de las consecuencias directas de su labor en torno al psicoanálisis ni por las reacciones provocadas por la lectura de su trabajo en tierras transandinas ni chilenas - de hecho esta fue la única pieza que produjo específicamente sobre el tema-, sino porque Freud comentó su escrito, en dos ocasiones, otorgándole estatus histórico. Si estas no hubiesen existido, lo más probable es que el trabajo de Greve en torno al psicoanálisis nunca se hubiese conocido.

La referencia más conocida data del año 1914 y proviene del conocido escrito Contribución a la historia del movimiento psicoanalítico (1914/1972). Allí Freud indica: "Un médico - probablemente alemán-de Chile defendió en el Congreso Médico Internacional de Buenos Aires, en 1910, la existencia de la sexualidad infantil y encomió los resultados de la terapia psicoanalítica en los síntomas obsesivos" " (Freud, 1914/1972). De este modo, Sigmund Freud hacía referencia del trabajo del médico chileno, de cuya procedencia no está muy seguro, ciertamente. Sin embargo, esta crónica tenía su predecesora, otro comentario de Freud -más extenso- de 1911 en la Zentralblatt für Psychoanalyse $e^{10}$, en el comenta con más detalle el análisis hecho por Greve ante el público trasandino, destacando la adhesión del chileno a los hallazgos de la sexualidad infantil y la experiencia clínica confirmatoria ante la cura de la neurosis obsesiva. Cierra Freud, diciendo: "Agradecemos al colega (probablemente alemán) en el lejano Chile, por la valoración imparcial del psicoa-

8 Para más antecedentes del Congreso, ver de M. Asúa: La fiesta de la ciencia (2011).

9 Las cursivas son mías.

10 Traducción realizada por el Dr. Juan Pablo Jiménez. El comentario original se encuentra disponible en Zentralblatt für Psychoanalyse (8 ed., 1, pp.594-595). nálisis y por la confirmación de su acción curativa en tierras lejanas. Freud" (Freud, 1911/1991, p. 595).

Esta pieza única, desde una perspectiva histórica, marca un hito en la recepción de las ideas freudianas tanto en Chile como en la Argentina. En términos idiomáticos, se puede llegar a afirmar que el trabajo de Greve fue una de las primeras referencias en español de las ideas de Freud, en nuestro continente. Hasta hace un tiempo se lo mencionaba como la primera en Latinoamérica (Etchegoyen \& Zysman, 2005), sin embargo, la evidencia muestra que ya en 1899, el doctor brasileño Juliano Moreira hacía mención a Freud en sus clases de psiquiatría en la ciudad de Bahía (Russo, 2012), evidenciado la temprana atracción que provocaban los conceptos psicoanalíticos en la región.

Volviendo a Greve, el viaje de la comisión de médicos que participaron en el Congreso en Buenos Aires fue cubierto por la prensa local. Así, la Revista Zig-Zag del 7 de mayo de 1910 le dedica una fotografía al grupo de médicos viajeros.

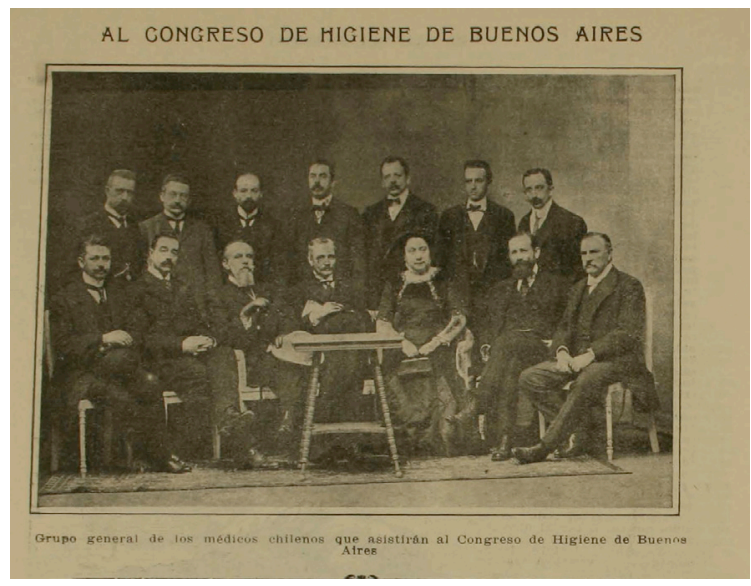

En la fotografía, sentados, el segundo de (izquierda a derecha) es Germán Greve Schlegel.

Definitivamente, en términos historiográficos, han sido muchos más los investigadores argentinos (García, 1980; Olagaray, 1989; Plotkin, 2003, 2009a, 2009b; Rosenthal, 1945; Vezzetti, 1996) quienes se han preocupado de valorar y analizar el trabajo de Greve, en comparación con investigadores nacionales. De hecho Hugo Vezzetti, por ejemplo, señala que 
"La mención que Freud hizo del trabajo de Germán Greve lo convierte en una referencia obligada de la historia del psicoanálisis en la Argentina" (Vezzetti, 1996, p. 17). Más aún, uno de los insignes traductores de las obras de Freud al español, Ludovico Rosenthal quien, en $1945^{11}$, habría recuperado este texto el que se hallaba "perdido entre otros folletos de esos que las bibliotecas encuadernan por rutina, hayamos el de Greve" (Rosenthal, 1945, p. 202). Rosenthal denuncia posibles complicaciones en la catalogación, registro y archivo del artículo del médico chileno que habrían facilitado su extravío. Personalmente, tuve la suerte de poder acceder sin mayor inconveniente al libro que, en 1911, reunía las ponencias del Congreso en las que se encontraba la de Germán Greve ${ }^{12}$. Esta nueva información es valiosa, ya que permite comprender detalles como: qué lugar ocupó el trabajo del chileno -y por ende el psicoanálisis-dentro del Programa del Congreso, con quién compartió mesa en su exposición y cuál era el clima de ideas en el certamen.

Germán Greve presentó su trabajo el 5 de junio de 1910, en la Cuarta Sesión del Congreso, la que fue presidida por los doctores Carlos Butler y Güemes ${ }^{13}$, participaron también como secretarios los doctores Sisto y Zabaleta. La mesa de trabajo estaba compuesta por los siguientes expositores:

Dr. Bauzá (Uruguay)

Valor semiológico de la esionofilia.

Dr. Greve

11 Vale la pena recuperar el relato de Rosenthal, quien dice: "Anunciada nuestra curiosidad -tras la mención de Freud de 1914 sobre Greve- tratamos de seguir la pista a esta noticia sobre la difusión del psicoanálisis en latitudes australes. El único certamen internacional celebrado en Buenos aires en aquel año fue el Congreso Científico Internacional Americano del Centenario (10 al 25 de junio de 1910), en cuyas actas corresponden a la Sección de Ciencias Psicológicas no se halla el trabajo de Greve, pero sí una serie de comunicaciones que revelan bien a las claras la absoluta égida continental de José Ingenieros. En cambio, perdido entre otros folletos de esos que las bibliotecas encuadernan por rutina, llamamos el de Greve, que se reproduce a continuación dado su valor para nuestro movimiento psicoanalítico" (Rosenthal, 1945, p. 202).

12 El trabajo de Greve se encuentra en las páginas 291-304. Hay una copia disponible para descargar online que fue donada por mí a la Biblioteca Nacional en el sitio de Memoria Chilena: http:// www.memoriachilena.cl/noticias/index.asp?id $=973056880$

13 No hay detalles del nombre de pila del doctor Güemes.
Sobre psicología y psicoterapia de ciertos estados angustiosos.

Dr. Agote

La palidez de los aórticos.

Drs. Agote y Facio

Los descensos estables del corazón.

Como se puede apreciar, el trabajo de Greve aparece en medio de una diversidad temática en su mesa de presentación, pero esto no solo lo afecta a él, sino que a la mayoría de los expositores de esta sección, destacándose más su aporte a la cura de las obsesiones que otra cosa.

En términos biográficos, Germán Greve Schlegel nació en Valparaíso el 19 de diciembre de 1869, cuidad donde hizo sus estudios primarios. Luego se trasladó a Santiago en el año 1882, donde ingresó al Instituto Nacional donde cursó la secundaria. Más tarde, sus estudios universitarios los realizó en la Universidad de Chile en el año 1886, titulándose como Farmacéutico en 1889. Greve provenía de una familia alemana donde la farmacia era una profesión tradicional. Su padre Germán Greve Lemcke se graduó de Farmacéutico en la Universidad de Rostock (Alemania), y años más tarde viajaría Chile estableciéndose en Valparaíso con la importadora Greve y Cía.

Posteriormente, el 3 de octubre de 1892, se tituló de Médico Cirujano también en la Universidad de Chile. Apenas recibido de médico, a comienzos de 1893, Greve con 24 años de edad, es comisionado por el Gobierno de Chile para recorrer Europa. Sobre este tema, muchos autores han planteado ideas sobre el propósito de este viaje, el que será crucial para el encuentro con las ideas freudianas. Por ejemplo: Whiting (1980) afirma que Greve "se traslado a Alemania donde se especializó en enfermedades nerviosas y mentales" (p. 20). Lo mismo señala Davanzo (s. f.) "el Dr. Germán Greve, formado en Alemania como neurólogo [...] (p. 58)”. Gomberoff sigue la misma línea cuando replica "En 1893, el Dr. Greve se había trasladado a Alemania a especializarse en enfermedades nerviosas y mentales [...]" (Gomberoff, 1990, p. 379). Y finalmente, de igual modo, Arrué declara "En el año 1893, después de titularse de médico y farmacéutico, viajó a Alemania donde se especializó en enfermedades nerviosas y mentales" (Arrué, 1990 en Casaula et al., 1991, p. 35). 
Germán Greve Schlegel y la Recepción del psicoanÁlisis en Chile: LA HISTORIA DE UN MÉdICO CHILENO "PROBABLEMENTE ALEMÁN"

La familia de Germán Greve amablemente me proporcionó información valiosa para la presente investigación. Así, y luego de analizar dichos antecedentes, puedo afirmar que: primero, Greve no fue un lector "situado" en Latinoamérica y que desde nuestro continente habría leído a Freud. Todo lo contrario. Segundo, la exposición de Greve en Buenos Aires en 1910 fue la consecuencia de varios años de contacto del médico chileno con las teorías psicoanalíticas, acompañando casi "en tiempo real" su desarrollo y transformación. Tercero, las razones del viaje de Greve dicen relación con una sentida necesidad nacional: la urgencia de construir nuevos manicomios a razón del aumento de la población interna de la Casa de Orates, las que denunciaban las malas condiciones habitacionales del establecimiento. Profundizaré con detalle estas ideas a continuación.

\section{Germán Greve Schlegel y Sigmund Freud en Viena (1894)}

La historia del encuentro de Greve con el psicoanálisis y, más específicamente con Freud en perso- na, se habría remontado a dieciséis años antes de la exposición en Buenos Aires. Fue en 1894, en el Congreso de Científicos Naturalistas y Médicos Alemanes en Viena. Hace unos años, tuve la oportunidad de colaborar con un trabajo que Michael Molnar (Molnar, 2010: Molnar, 2011). - exdirector del Museo Freud de Londres- realizó sobre la fotografía de este Congreso (N.. 1626 del catálogo) contenida en el banco fotográfico de dicha entidad. Esta pieza era un regalo para los asistentes a dicho encuentro, Molnar (en Londres) y yo (en Santiago) teníamos las respectivas copias de la fotografía ${ }^{14}$, él la de Freud y yo la de Greve. Efectivamente, la copia de Greve tenía el valioso detalle que al pie de la fotografía el médico chileno se encargó de registrar a muchos de sus colegas que posaron en esa ocasión. El cruce de ambas fuentes permitió la identificación de varios participantes. Greve había partido a Europa en 1893, su estadía duró cinco años (1893-1898), donde recorrió diferentes clínicas y universidades de

14 Para más antecedentes, ver Molnar $(2010,2011)$.

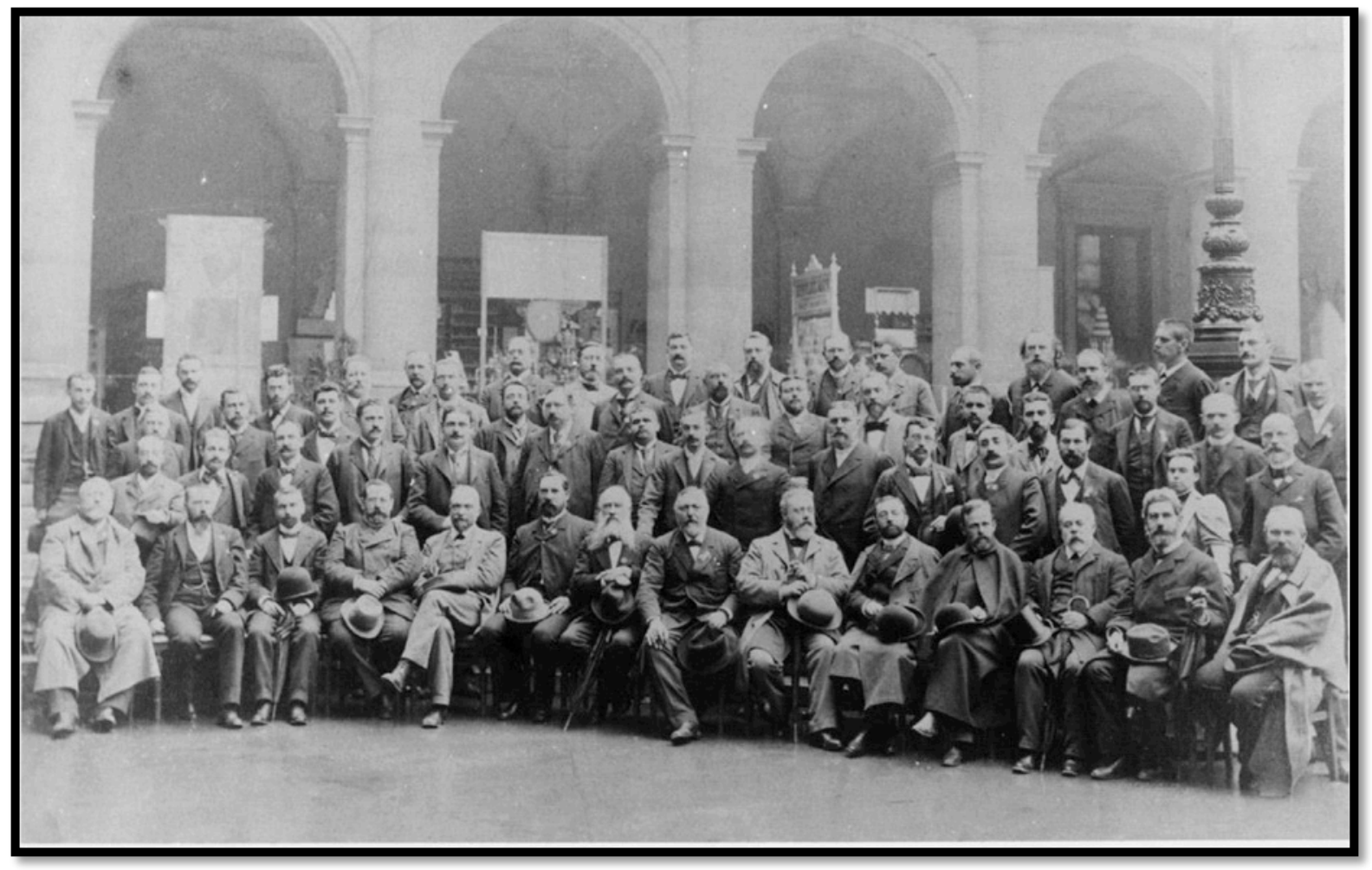


Alemania, Austria y Francia. Inclusive, se afirma que habría trabajado en el laboratorio del fisiólogo Rudolf Virchow. Las razones de su viaje se aclaran en lo relatado en su biografía (no publicada) escrita por su hijo Germán Greve Silva (1969) ${ }^{15}$ :

Obtuvo su título de Farmacéutico en el año 1889 y el título de Médico Cirujano el 3 de Octubre de 1892. Se trasladó después a Europa a perfeccionar sus estudios médicos y recibiendo la Comisión de Gobierno, de estudiar e informar acerca de los progresos de la Electroterapia y de los Manicomios, informes que presentó a las autoridades correspondientes y que fueron publicados en la "Revista Médica de Chile" en los años 1894 y 1895. [Y agrega] Siendo muy

15 Este material también me fue proporcionado por la familia Greve. joven, se posicionó en los grandes centros médicos del Viejo Mundo de los primeros progresos de la electroterapia. (p. 1)

\section{Fotografía del Congreso de Científicos Naturalistas y Médicos Alemanes en Viena, 1894.}

Entonces, como muestra la fotografía, Greve asistió al Congreso donde también estaba Freud. El registro de la correspondencia de Freud con Fliess entrega antecedentes de su participación en dicho encuentro. Esto se puede detectar en la carta del 7 de febrero de 1894 donde afirma: "No sé si ya te he escrito que en la reunión de naturalistas de setiembre tengo que oficiar de primer secretario de la sección neurológica. Espero verte en esa ocasión, y muchas veces entre nosotros" (Freud, 1894/1994, p. 61).

La inscripción de la fotografía dice así (Molnar, 2011):

66을 Encuentro de Científicos Naturalistas y Médicos Alemanes 24-30 de Septiembre 1894.

Psiquiatría y Neurología.

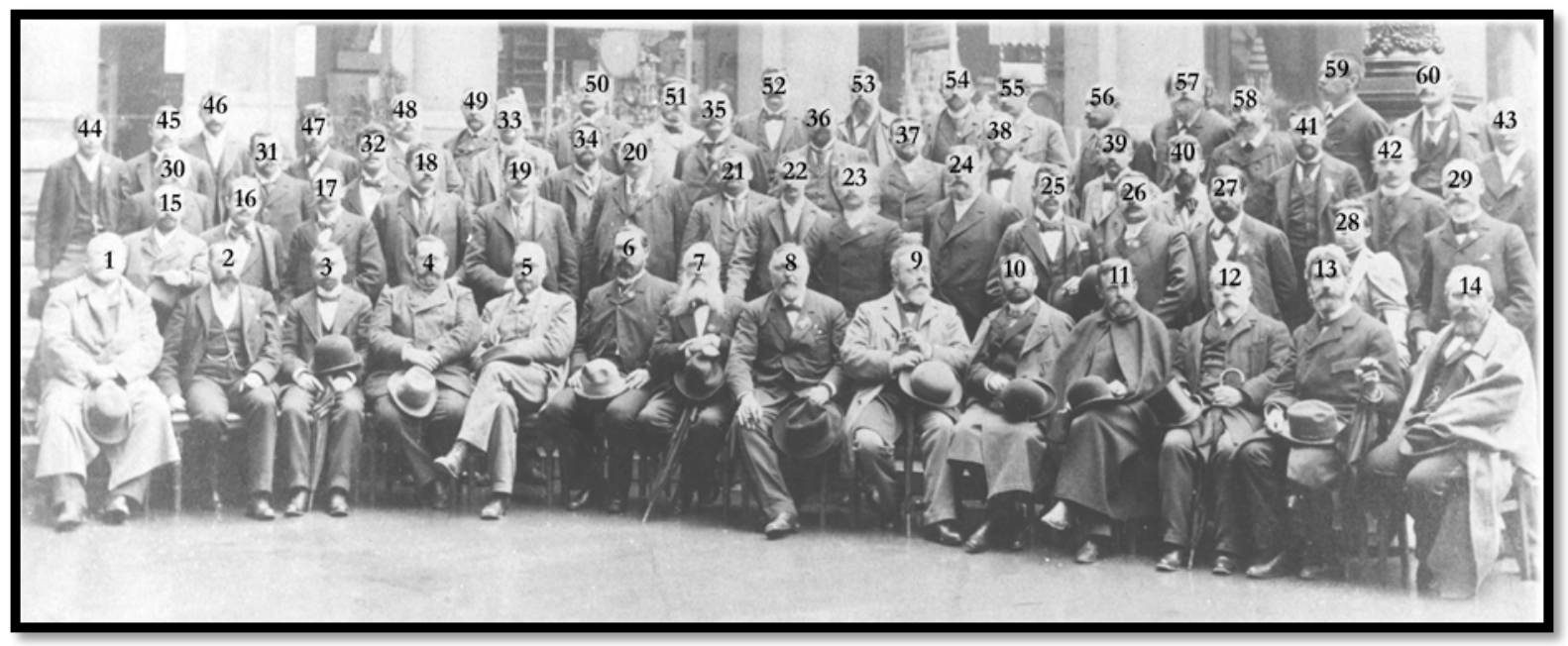

Identificación de algunos participantes:

1. Max Kassowitz (1842-1913). 3. Otto Binswanger (1852-1929). 4. Albert Moll (1862-1939). 5. Auguste Forel (1848-1931) 6. Constantin v. Monakow (1853-1930). 7. Karl Ludwig Kahlbaum (1828-99). 8. Richard Krafft-Ebing (1840-1902). 9. Friedrich Jolly (1844-1904). 10. Gabriel Anton (1858-1933). 11. Heinrich Obersteiner (1847-1922). 12. Salomon Stricker (1834-1898). 18. Karl Mayer (1862-1936). 21. Emilio Conde Flores (1869-1928). 22. Germán Greve Schlegel (1869-1954). 25. Max Herz (1865-?). 26. C.S. Freund. 27. Sigmund Freud (1856-1939). 28. Frau Dr. v. Leonowa. 33. Smith. 35. Alois Alzheimer (18641915). 36. Emanuel Mendel (1839-?). 40. Pinele [Pineles?]. 41. Lothar Frankl-Hochwart (1862-1914). 47. Alexander Spitzer. 50. Stüver. 51. Hirschl. 55. Robert Sommer. 59. Julius Wagner-Jauregg (1857-

Tomada en el Patio de los Arcos de la Universidad 


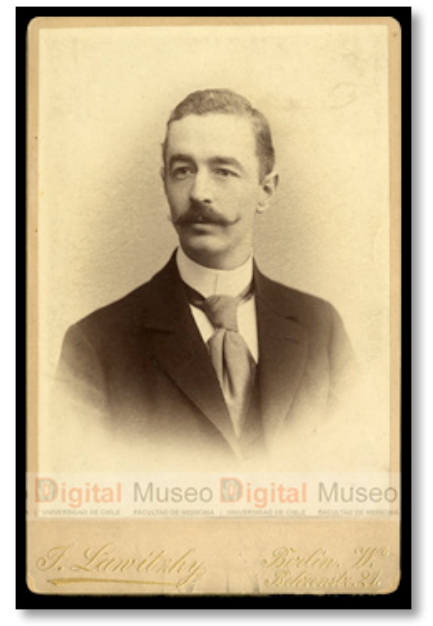

Fotografía de Germán Greve Schlegel tomada en Berlín en la época de su viaje.

\section{"Sobre psicología y psicoterapia de ciertos estados angustiosos" (1910): Un encuentro reservado y una práctica privada}

Germán Greve Schlegel, quien posa junto con el médico venezolano Emilio Conde Flores ${ }^{16}$, son los dos únicos latinoamericanos que han podido ser identificados hasta ahora en la fotografía. Greve Silva (1969) agrega lo siguiente:

Durante sus estudios en Europa, principalmente en las Universidades de Berlín, en Alemania, Viena, en Austria, tuvo la oportunidad de observar la labor de grandes maestros y eminencias de la medicina de esa época, siendo alumno de ilustres figuras de esa ciencia, alternando con profesores de renombre universal tales como Mendel, Jolly, Siermerling, Freud, von Jauregg, Virchow, Kraft-Ebing, Wagner, Obersteiner, Neusser y Orten. [Luego profundiza]: También entabló gran amistad con el famoso Prof. Dr. Siegmund Freud, eminencia de la psiquiatría universal y con el cual, después de su regreso a su patria,

16 Emilio Conde Flores (1869-1928) por esa época desempeñaba el cargo de Cónsul de Venezuela ante el Imperio Austro-Húngaro. Lo mismo que Secretario de la Embajada Venezolana. Permaneció en Europa, tras un amplio recorrido de perfeccionamiento, hasta el año 1895, fecha en la que volvió a Venezuela para desempeñarse como Otorrino. mantuvo durante varios años nutrida e interesante correspondencia, en la que el Dr. Greve le daba a conocer las experiencias y conclusiones logradas en el estudio y práctica de la psiquiatría, muchas de las, muchas de las cuales fueron reconocidas y citadas por Freud en sus trabajos publicados. (p. 1)

Como se ve, estas referencias hablan de que Greve habría conocido personalmente a Freud y que a su regreso a Chile sostuvo un contacto regular con él. Esto permitiría comprender el interés y la forma en la que el médico chileno se mantuvo informado de los desarrollos del psicoanálisis, por lo menos hasta su viaje a Buenos Aires en 1910. Ludovico Rosenthal (1945) declara "Hemos revisado el catálogo de la obra freudiana mientras recorríamos las páginas de este folleto, llegando a la conclusión de que su autor debió haber leído, no sólo la primera serie de las Kleine Schriften zur Neurosenlehre (1906), sino también la segunda editada recién en 1909, celeridad informativa que revela la inquietud por el psicoanálisis" (p. 202). Si hay algo que sorprende de la historia de Greve es el silencio y la reserva que mantuvo sobre el tema en el periodo de 1894 a 1910; pensando además que Greve fue un médico prolífico en términos editoriales. Además, hasta ahora, no existe registro alguno de la supuesta correspondencia entre ellos, ni en Viena, Londres o la Biblioteca del Congreso de Estados Unidos. Lo mismo que en los catálogos de los documentos y libros de Freud, donde no existe ni una copia del trabajo de Greve, pero sí de otros médicos chilenos como Fernando Allende Navarro o Juan Marín. De hecho, este "silencio" también está presente en Greve, quien escribía regularmente a su contraparte y maestro Augusto Orrego Luco los hallazgos de su viaje en la llamada Correspondencia Europea, cuyas cartas entre ellos fueron publicadas en la Revista Médica entre los años 1894 y 1895 (Greve, 1895), en dicha sección. En esas cartas, Greve no hace ninguna referencia a Freud, sus desarrollos o lecturas que haya realizado sobre el psicoanálisis en alguna revista especializadas de la época ${ }^{17}$. Más adelante,

17 No hay que olvidar que como lo muestra Sylvia Zwettlwe-Otte 
inclusive, en el año 1899 asumirá la dirección de la Revista Médica hasta el año 1902, lugar donde no se publicará nada relacionado con el psicoanálisis (Cruz-Coke, 1995). Lo mismo pasará en el Cuarto Congreso Científico (1. - Pan-Americano), celebrado en Santiago entre diciembre y enero de 19081909, donde la V Sección del certamen "Ciencias Médicas e Higiene" estuvo a cargo de Greve, pero tampoco existió ninguna referencia a Freud ${ }^{18}$.

El investigador Ramón León (1982) plantea:

No hemos podido determinar cómo llegó este trabajo a las manos de Freud. Una posibilidad es que el mismo Greve le remitiera el texto de su conferencia. En todo caso, lo positivo es que el trabajo, por su valor y/o por el hecho de ser el primero en mencionar al psicoanálisis en castellano, despertó el interés de Freud quien preparó una recesión del mismo (Freud, 1911) aparecida en Zentralblatt für Psychoanalyse. (p. 173)

A mi modo de ver, no cabe duda que Greve le envió directamente una copia de su trabajo a Freud $^{1919}$, quien se sintió motivado a comentarlo en virtud de la expansión del psicoanálisis, en lo que llamó "tierras remotas".

Zentralblatt für Psychoanalyse fue un proyecto editorial del grupo de Viena, tras el Congreso Internacional de Psicoanálisis realizado en 1910 en la ciudad de Núremberg. La dirección de la revista estaría a cargo de William Stekel y Alfred Adler, pero Freud tendría participación como editor, con la potestad de censurar alguna publicación que le pareciera inadecuada (Freud, 191471972) ${ }^{20}$. Las rese-

(2006), desde 1895 revistas como Wiener Klinische Wochenschrift ya publicaban comentarios sobre el trabajo de Freud.

18 En dicho encuentro presentaron trabajos distintas personalidades entre ellas Eloísa Díaz (primera mujer médico en Chile y Latinoamérica) con su trabajo "La Higiene Escolar en Chile".

19 El investigador argentino Mauro Vallejo comparte esta impresión: "Sin lugar a dudas, el médico envió al maestro vienés una copia de su trabajo, y éste decidió escribir una reseña del mismo en la primera revista editada por los miembros de la Sociedad Psicoanalítica de Viena”. En Vallejo, M. (2010). Reseña que escribió Freud acerca de la primera conferencia sobre teoría psicoanalítica en Argentina (1910). En Imago Agenda [online]. Disponible en: http://www.imagoagenda.com/articulo.asp?idarticulo=1293

20 Comenta Freud (1914): "Otra consecuencia del Congreso de Núremberg fue la fundación de la revista Zentralbaltt für Psychoanalyse, para la cual se unieron Adler y Stekel. Originariamente ñas bibliográficas fueron un punto de preocupación para Freud, quien deseaba mayor atención en esta sección de la revista. Pensó inclusive en otorgarle la responsabilidad de ella a Victor Tausk ${ }^{21}$, ante la férrea oposición de Sketel. Ernest Jones, biógrafo de Freud, al comentar este episodio entrega noticias de Greve. Dice así: "Pero Freud, si bien alguna vez había dicho que Tausk era una "bestia salvaje", tenía una opinión muy elevada de su capacidad y precisamente entonces quería que se encargara de la sección bibliográfica de la Zentralblatt, que se hallaba muy descuidada. (Diremos de paso que las únicas reseñas que Freud escribió para la revista se refería a un libro popular de Neutra y un libro en español, de Chile)" 22 (Jones, 1997, pp. 149-150).

En definitiva la reseña íntegra de Freud (1911) dice así:

G. Greve, Sobre Psicología y Psicoterapia de ciertos Estados angustiosos. (Discurso brindado ante la Sección neurológica del Congreso Internacional Americano de Medicina e Higiene, Buenos Aires, mayo de 1910).

El autor, que asistió al Congreso en calidad de delegado del Gobierno de Chile, expuso de un modo especialmente claro, y libre de malentendidos, el contenido esencial de la doctrina de la represión y el significado etiológico de los momentos sexuales para las neurosis. Con digna modestia, se abstiene de dar un juicio definitivo sobre toda la doctrina; su experiencia, opina, no le permite decir algo más, pues no ha conducido el análisis más allá de las causas puberales de la enfermedad ( $y$ aun cuando nos mostramos reservados para emitir una opinión propia, se nos ha de

tenía este proyecto una franca tendencia oposicionista y entrañaba el propósito de reconquistar para Viena la hegemonía, amenazada por la lección de Jung. Pero cuando los dos fundadores tropezaron con la dificultad de hallar un editor y acudieron a mí asegurándome sus intenciones pacíficas, en prenda de las cuales me concedieron un derecho a veto, tomé a mi cargo la publicación del nuevo órgano, cuyo primer número apareció en septiembre de 1910" (p. 1917).

21 Un trabajo interesante sobre Victor Tausk es el de P. Roazen (1994).

22 Las cursivas son mías. Más en: Jones, E. (1997). Esta particularidad ya había sido comentada por mi profesor y desaparecido amigo Jorge Olagaray Otero (1990). 
perdonar, ya que nuestra experiencia personal no alcanza a abarcar toda la altitud de sus doctrinas).

Con todo, numerosas afirmaciones no dejan lugar a dudas sobre las convicciones con las que él simpatiza. La existencia de la sexualidad infantil le parece demostrada con certeza a través de las investigaciones presentes (demostrada hasta la evidencia); él y otros (todos nosotros) podrían tener la oportunidad de observarla en niños neuróticos, en los cuales aparece con una cierta tendencia hacia la exageración. Incluso, la aplicación de un tratamiento analítico incompleto logra alcanzar, en una mayoría de los casos, una considerable mejoría del estado psicológico general, de tal manera que los pacientes recuperan su capacidad de rendimiento, aun cuando los síntomas persistan con una intensidad disminuida (...para traer una notable mejoría del estado general psíquico del paciente, aun cuando puedan seguir persistiendo síntomas que, por su poca acentuación, no aparenten enfermedad y no lo inutilicen para la sociedad.) (Ref. quisiera destacar: muy especialmente el buen entendimiento de las enfermedades neuróticas que trasluce el buscar el éxito curativo, no en la remoción de síntomas aislados, sino en la instalación de la capacidad de vivir). El autor considera a la neurosis obsesiva como especialmente accesible a la terapia analítica; refiere a que él fue posible una vez, en dos conversaciones en confianza y que en conjunto no completaron una hora, remover ideas obsesivas que habían resistido tenazmente a los otros tratamientos. El autor invita a sus colegas a brindar la máxima atención a las doctrinas en cuestión; éstas estarían fundadas en cuidadosas investigaciones y se podría extraer de ellas muchas cosas cuya aplicación sería de mucha utilidad para sus enfermos. (Pero insisto ante vosotros, que de un atento estudio de las teorías de F., teorías basadas en la más escrupulosa y paciente observación de hechos clínicos que se pueda exigir, podréis cosechar mucho, muchísimo que puede favorecer á vuestros enfermos).

Agradecemos al colega (probablemente alemán) en el lejano Chile por la valoración imparcial del psicoanálisis y por la confirmación inesperada de su acción curativa en tierras lejanas. Freud.

Como lo anunciaba, siguiendo a Plotkin (2009a, 2009b), el trabajo de Greve (1910) se destaca por el modo en que presenta las ideas freudianas: tratando de hacerlas coincidir con los postulados del francés Pierre Janet. Greve plantea acerca del psicoanálisis:

Resumiremos, en cuento nos sea posible para no perder en claridad, el desarrollo actual que tiene esta doctrina, tal cual la comprendemos nosotros, doctrina que desde que se empezó a desarrollar, ha seguido evolucionando hasta constituir la base de toda una nueva psicología. A que preferentemente hemos de abordar, y permítasenos poner frente a frente la opinión que Freud tiene sobre la etiología primera de la neurosis, con la que Janet ha emitido sobre la misma cuestión, ya que quisiéramos hacer notar las concordancias de ambas, a fin de conciliarla con opinión tan distinguida ${ }^{23}$ ( (p. 291)

Este esfuerzo reflejaría el dominio que la mirada gala tenía en la escena médica de la época y la región. Continúa Plotkin: "En Argentina, donde la influencia de la cultura francesa era de suma importancia, el psicoanálisis fue leído originariamente en francés (es decir, a través de fuentes francesas o, más comúnmente, a través de comentaristas de esa nacionalidad) y filtrado por la lente de las teorías psiquiátricas francesas" (Plotkin, 2009a, p. 66). En este mismo sentido, recordemos que a la vista de Greve, el campo de las teorías de las neurosis era variado, pero reconoce una raíz común: los postulados de Jean Martín Charcot. Lo dice así: "El problema [de las neurosis] ha sido abordado, por distinguimos investigadores, desde los más distintos puntos de vista, pero teniendo siempre presente la clásica nosografía de Charcot. En efecto, a pesar del aparente antagonismo de las opiniones emitidas, hay en todas ellas, o en casi todas, un fondo común que revela un culto a las lecciones del insigne maestro $24 "$ (p. 292).

Por lo tanto, no me queda más que confirmar que, del lado chileno, esta impresión se cumple a cabalidad. Los médicos nacionales admiraban y seguían de manera pormenorizada los desarrollos

23 Las cursivas son mías.

24 Las cursivas son mías. 
de sus pares franceses ${ }^{25}$. De hecho, la cátedra de Neurología y Enfermedades Nerviosas y Mentales fue creada en la Universidad de Chile -único establecimiento público que impartía estas enseñanzasen 1889 a cargo del médico chileno-francés Carlos Sazié, quien estudió en Francia con Charcot en La Salpetrière. Sazié ocuparía el cargo hasta 1891 -año en que se inició la Guerra Civil en Chile en contra del gobierno del Presidente Balmaceda, del cual Sazié era partidario- siendo reemplazado por $\mathrm{Au}$ gusto Orrego Luco, político, historiador, psiquiatra, y finalmente, maestro de Greve y de igual inspiración organicista, quien envió al maestro parisino en 1882 un estudio sobre la histeria traumática, que fue publicado en la revista Iconographie de La Salpetrière (Orrego, 2002). Así, el énfasis organicista de la escena neuro-psiquiátrica nacional, claramente influenciada por el pensamiento francés de Jean Martín Charcot y su método anatomoclínico se verán reflejadas en la búsqueda de las lesiones orgánicas que definieran y propiciarían los trastornos mentales (Roa 1974, 1980).

En esta misma línea lo harán sus sucesores Joaquín Luco, Oscar Fontecilla y Arturo Vivado, hasta bien entrados los años 40. Esta época estaría marcada por la búsqueda de las lesiones orgánicas que definieran y propiciarían los trastornos mentales. Este estilo "somático" circunscribía, además, las alternativas terapéuticas entre las que se encontraban métodos como la cardiazolterapia, insulinoterapia y terapia electroconvulsiva o electroshock. Su presencia puede detectarse desde principios de la década de 1880 (Araya \& Leyton, 2009). A diferencia de otros países, por ejemplo Estados Unidos y Argenti$\mathrm{na}^{26}$, donde se produjeron crisis relacionadas al auge del positivismo y del estilo somático en psiquiatría, la medicina psiquiátrica en Chile buscará ganar

25 La admiración por el mundo francés quedó plasmada en el juicio que hizo el historiador chileno Jaime Eyzaguirre quien, refiriéndose a los intelectuales nacionales: "no sólo las ideas liberales eran recibidas como panacea [...], vivía esta con la mirada estática en dirección a París, que le dictaba sin apelaciones las leyes del pensamiento, del vestuario y de la gastronomía" (Eyzaguierre en Gazmuri, Zaldívar, González, Piña, Machica, \& Muesca, 2007, p. 11).

26 Sobre el estilo somático y su posterior crisis en Estados Unidos y Argentina, respectivamente, ver Hale (1995) y Plotkin (1996a). reconocimiento científico apegándose más todavía al paradigma materialista (somático) y anclándose en una mirada hereditaria de los trastornos mentales. Lo anterior, establecerá cierta distancia con los descubrimientos del psicoanálisis, ya que, según el médico chileno, instala la noción de psicogénesis ${ }^{27}$.

Volviendo a la exposición de Greve, el chileno llega a afirmar inclusive que: "Verdaderamente no encontramos, aparte de los términos en que se expresan, diferencia alguna en la concepción de las neurosis que ambos autores manifiestan tener" (p. 292), evidenciado que el psicólogo francés tenía mucha más respetabilidad y prestigio local que Freud, por lo que convenía darlo a conocer como próximo. Para el médico chileno, uno de los puntos de fricción más notables de la teoría de Freud con el mundo médico es precisamente la sexualidad como causa de las neurosis. Lo dice así: "La teoría más rudamente combatida es, sin duda, la del profesor vienés Freud; la importancia que da a la sexualidad en la génesis de las neurosis, es la causa de los más acerbos ataques en much a parte anticientíficos y preocupados, como no era de esperarlo de otro modo en materia en que predominan las más arraigadas convicciones de orden convencional y social"28 (p. 292).

Greve evidencia que para la confección de su trabajo se basó en la lectura de Las neurosis (1909) de Pierre Janet ${ }^{29}$, Estudios sobre la histeria $(1885)^{30}$ de Freud y Breuer, La interpretación de los sueños

27 Greve afirma: "Freud, partiendo de la base que la histeria es una neurosis psicogénica, quiso llegar a conocer el mecanismo por medio del cual llegan a producirse síntomas histéricos y ha llegado a conclusiones, no sólo con relación a ésta, sino que también ha conseguido arrojar la luz sobre el mecanismo de formación de las obsesiones, de las neurosis obsediante, estableciendo que tiene una base común psicogénita de formación, por actuación de ideas inconscientes y digna de ser conocida" (p. 292).

28 Las cursivas son mías.

29 Más antecedentes en Saurí (1984).

30 "Nadie que tenga cierta práctica en la observación de histéricos pude negar el rol que desempeñan en la génesis de estos síntomas los estados afectivos y Freud trataba, ante todo, de establecer las íntimas relaciones de causa y efecto que necesariamente debían existir entre él o una serie de traumatismos psíquicos generadores y los síntomas mórbidos. Estas investigaciones llegaron a establecer, en compañía de Breyer, que ese traumatismo psíquico, no obraba como agente provocador cualquiera, pues a pesar de su caducidad, seguía substituyendo su acción". Y puntualiza: "Esta es la base de su aforismo que los histéricos padecen, en su mayor parte, de reminiscencias de carácter penoso [...]” (p. 293). 
(1900), Psicopatología de la vida cotidiana (1901) ${ }^{31}$, Tres ensayos de teoría sexual (1905) ${ }^{32}$, y sustancialmente La moral sexual "cultural" y la nerviosidad moderna (1908) de la autoría exclusiva de Freud. Greve elabora una exposición detallada sobre las psiconeurosis de defensa, teniendo a la sexualidad como un elemento crítico y traumático para el sujeto que vive en sociedad. Destaca además, las transformaciones que la teoría ha experimentado: "Esta teoría de las psiconeurosis de Freud no ha sido emitida desde un principio en la forma que la he descrito. Ha sufrido modificaciones substanciales conjuntamente con el método psicoterápico o "psicoanalítico", como lo llama el mismo autor, a que ha dado origen; ha evolucionado en el transcurso de los años de tal forma, que se han ido completando mutuamente: el "psicoanálisis" ha suministrado continuamente el material comprobante de la teoría y también el material sobre el que se basan las modificaciones sucesivas que el autor ha ido haciendo en aquella" (p. 300).

Como Greve estuvo en Europa hasta 1898, es muy probable que haya leído los escritos de Freud de primera fuente y los comentarios de los trabajos psicoanalíticos de esta época en revistas especializada, tales como Wiener Medizinische Wochenschrift y Wiener Klinische Wochenschrift ${ }^{3333}$, y luego haya seguido su evolución a su regreso a Chile, poniendo atención a las últimas publicaciones en el campo de la psiquiatría y psicología ${ }^{34}$. Entonces, queda

31 "Con este fin ha ideado Freud su arte especial de interpretación de las ocurrencias; con el cual, no sólo elabora los pensamientos involuntarios que recoge en esas sesiones de confidencias, sino que también sus sueños a los que considera la puerta de acceso más directa para llegar al conocimiento del inconsciente, los actos involuntarios como desordenados que se presenten como síntomas del mal y, por fin, los yerros de su vida diaria, como ser los lapsus linguae, las equivocaciones, distracciones, etc." (p. 301).

32 "Para este autor, la sexualidad infantil o, si se quiere, su disposición sexual, constitucional, es "polimorfamente perversa", para emplear su propia expresión [...]” (p. 295).

33 Una investigación importante que abre opciones para pensar en las fuentes de Greve es la de Sylvia Zwettler-Otte (2006).

34 "De sentir es la falta de una exposición detallada y puesta al día de la doctrina, uno de cuyos fascículos nos ha ocupado este momento. Es desparramamiento de las diversas partes, de que se compone aquella en distintos estudios, se agrega a la dificultad, bien grande por cierto, de comprensión de la materia, y la confusión se hace mayor, por las modificaciones que han ido experimentando en los diversos problemas y concepciones de que se compone. Agréguese a todo esto el idioma, estilo y forma de aclarado un aspecto en torno a Greve: su lectura de Freud no se hizo a través de comentaristas franceses, sino que directamente del alemán. Es verdad que muchos chilenos leyeron a Freud a partir de fuentes francesas ${ }^{35}$, especialmente en la década de los 20 -las que eran mayormente críticas a las ideas freudianas-, a partir de obras tales como las de J. Laumonier con Le freudisme: Exposé et critique (1925), Emmanuel Régis y Angelo Hesnard con La psychanalyse des névroses et des psychoses, ses applications médicales et extra-médicales (1914), de Angelo Hesnard también La psychanalyse. Théorie sexuelle de Freud (1924). Lo mismo pasaba con los trabajos del psicólogo y educador suizo Pierre Bovet con su obra La psychanalyse et l'éducation (1920/2008).

El médico chileno reconoce la dificultad propia del método clínico psicoanalítico, el tiempo que requiere de trabajo (promedio de tres años) con los pacientes, al parecer está relacionado con la complejidad del caso. Lo que sí queda claro es que Greve practicó de forma privada el psicoanálisis en Chile a su regreso de Europa:

La sola exposición de este método y las dificultades, aparentemente sin fin, que presenta, bastarían para desistir de emplearlo, si no fuera porque el método aplicado a medias ya es suficiente, en un gran número de casos, para traer una notable mejoría del estado general psíquico del paciente, aun cuando puedan seguir persistiendo los síntomas que, por su poca acentuación, no aparenten enfermedad y no lo inutilicen para la sociedad. Es este último método incompleto el que nosotros hemos aprovechado y con éxito que nos ha asombrado por su eficacia, para tratar casos rebeldes de neurosis obsediante, siempre que reúnan las condiciones de inteligencia, normalidad y de carácter, edad, etc., que estima Freud como los más a propósito para ser sometidos a este sistema de psicoterapia. (p. 303)

esas publicaciones, y se tendrá la clase de los móviles que nos han inducido emprender la labor para presentaros esta compendiada exposición de una parte de la doctrina” (p. 304).

35 De hecho en Santiago existía la llamada "Librairie Française", ubicada en la calle Huérfanos (Casilla 43D) -artería importante del centro cívico de la ciudad-, más específicamente en la denominada Casa Francesa. Esta librería importaba estas obras poniéndolas a disposición del público local. 
El análisis no es para todos, ya que Greve solo lo logra implementar con una selección adecuada de pacientes, lo que hace suponer que se trata de pacientes que provienen de la elite santiaguina ${ }^{36}$. Esa es una primera barrera que debe sortear, por lo que su práctica es restringida, incompleta y trabaja sobre un factor, la sexualidad, que es al menos complicado ${ }^{37}$.

Finalmente, Greve cierra su trabajo reconociendo una especie de deuda con Freud al que reconoce como su maestro. Será la última vez que se referirá públicamente al psicoanálisis: "Hemos cumplido señores, con un deber, rindiendo en esta solemne ocasión, homenaje a un antiguo maestro y lo hacemos, con tanta mayor satisfacción, cuanto que por sus teorías ha sido atacado con animosidad inusitada" (p. 304).

\section{Consideraciones finales}

La historia indica que más allá de su trabajo en Buenos Aires, Greve no profundizó en el psicoanálisis o por lo menos no volvió a publicar nada sobre el tema. Se volcó a la práctica psiquiátrica privada, incursionando en la criminología y formando parte de la Asociación de Beneficencia Pública desde 1918. Además, fue Director durante veintitrés años de la Revista de Beneficencia Pública, siendo rebautizada, en la década del treinta Revista de Asistencia Pública. También fue subadministrador de la Asistencia Pública y administrador de los servicios hospitalarios, consolidándose como un gran exponente de las ideas del higienismo. Lo anterior, a mi modo de ver, implicaría que este médico chileno concentró su trabajo en varios temas de alta sensibilidad social. Varios teóricos se han referido al alejamiento de Greve del campo psicoanalítico, llegando a imputar razones tan variadas como su supuesta

36 Greve tenía su consulta particular en la calle Agustinas № 1954 , en el centro de Santiago.

37 "Cómo se ve no pasamos más allá en nuestros psicoanálisis que de la época de las fantasías de la pubertad y no alcanzamos a analizar la vida sexual de la primera infancia que, por lo demás, no es abordable sin el método de interpretación de Freud y, sin embargo, logramos un alivio que en más de uno no fue posible conseguir con los métodos ordinarios de tratamiento" (p. 304). personalidad conservadora, muy respetuosa de los cánones morales de la época (Whiting, 1980) o la falta un soporte institucional psicoanalítico (Olagaray, 1990), ambas barreras que le habrían impedido ejercer una función más "activa" en la difusión local de las ideas de Freud ${ }^{38}$. A mi modo de ver, como se veía, la conformación de la escena psiquiátrica local, su predominante estilo somático -influenciado fuertemente por una postura anatomopatológica- redujeron significativamente las posibilidades de Greve de insertar el psicoanálisis en el círculo médico chileno. La influencia francesa hizo que los médicos chilenos rechazaran el psicoanálisis por ser poco científico, fuertemente especulativo, concentrando sus esfuerzos en el polo fisiológico de las enfermedades mentales. Si bien el psicoanálisis era conocido por los médicos chilenos, sus postulados no tuvieron mayor repercusión hasta mediados de la década del 20, por lo menos en el mundo médico. En esta época los conceptos psicoanalíticos fueron más discutidos y criticados por los participantes de la incipiente escena psiquiátrica local (Allende Navarro, 1925).

Lo que sí queda claro al final de este trabajo es que Germán Greve participó de un entramado de relaciones que condicionaron e influyeron su lectura, práctica y exposición dentro del campo del psicoanálisis. Su contacto con las ideas freudianas habría sido de primera fuente, gracias al impulso del Gobierno chileno de la época para que varios médicos recorrieran los grandes "centros de producción del saber" con el fin de importar dichos conocimientos a nuestro país. Vale la pena pensar en los intentos de Greve por hacer coincidir los postulados de Freud con los de Janet con el fin de intentar superar los filtros presentes en el campo médico. Ya el psicoanálisis para los médicos locales presenta la dificultad de ser practicado según la orientación freudiana, lo que obliga a muchos de los practicantes a hacer variaciones, generando los esperados efectos de la recepción de una nueva práctica que se adecúa a las condiciones particulares de su lugar

38 Greve en 1925 al incorporarse como profesor a la Facultad de Medicina leyó el trabajo "El influjo del espíritu en el cuerpo", donde no hizo ninguna mención a las ideas de Freud. 
Germán Greve Schlegel y la Recepción del psicoanálisis en Chile: LA HisToria de UN MÉdiCo CHILENo "PROBAblemENTE ALEMÁN"

de arribo. En este sentido, la lectura que hace Greve del psicoanálisis refleja cómo la sexualidad -como tema fundamental del freudismo- tenía sus dificultades para ser tratado en términos médicos. Sin embargo, esta escena cambiará significativamente, ya que desde la década de los años veinte la sexualidad superará el ámbito de lo privado para convertirse en un asunto público, facilitando la recepción del psicoanálisis. Este giro, finalmente, revalorará el psicoanálisis precisamente por el mismo factor que era rechazado en la época de Greve: la sexualidad. Hablar de psicoanálisis será sinónimo de un saber especializado sobre la sexualidad y sus modos de canalizarla hacia metas elevadas, gracias a la acción de la sublimación (Ruperthuz, 2012).

\section{Referencias}

Agote, L. (1911). Actas y trabajos. Congreso Americano de Medicina e Higiene. Buenos Aires 1910 (Sección II-Medicina y sus clínicas). Buenos Aires: Establecimiento Gráfico M. Pastor \& Cía.

Allende Navarro, F. (1925). El valor del psicoanálisis en la policlínica. Contribución a la psicología clínica. Santiago: Universitaria.

Araya, C., \& Leyton, C. (febrero, 2009). Atrapados sin salida: terapias de shock y la consolidación de la psiquiatría en Chile, 1930-1950. Nuevo Mundo. Mundos Nuevos. Recuperado de http://nuevomundo.revues.org/52793

Ardila, R. (1998). La psicología en Latinoamérica: pasado, presente y futuro. México: Siglo XXI.

Aróstegui, J. (2003). La investigación histórica: teoría y método. Barcelona: Crítica.

Arrieta, L., \& Gomberoff, L. (2007). Préhistoire et premiers pas de la psychanalyse au Chili. Topique, 98(1), 159-169.

Arrué, O. (1990). "Orígenes e identidad del movimiento psicoanalítico chileno”. En Casaula, E., Coloma, J. \& Jordan, J.F. (1991). Cuarenta años de psicoanálisis en Chile. Biografía de una sociedad científica Santiago: Ananké, pp.23-51.

Bovet, P. (2008). Psicoanálisis y educación. En P. Jiménez \& R. Páez (Comps.), Deseo, saber y transferencia. Un acercamiento psicoanalítico a la educación. Buenos Aires: Siglo XXI.
Breger, L. (2001). Freud, el genio y sus sombras. Barcelona: Vergara.

Briggs, A., \& Burke, P. (2007). De Gutemberg a internet. Una historia social de los medios de comunicación. México: Taurus.

Casaula, E., Coloma, J., \& Jordan, J. F. (1990). Cuarenta años de psicoanálisis en Chile. Santiago: Ananké.

Cruz-Coke, R. (1995). Historia de la medicina chilena. Santiago: Andrés Bello.

Dagfal, A. (2004). Por una "estética de la recepción" de las ideas psicológicas. Frenia, 4(2), 7-16.

Davanzo, H. (1993). Orígenes del psicoanálisis en Chile. Coloquio con Arturo Prat E. y Ramón Ganzaraín. Revista Chilena de Psicoanálisis, 10(2), 58-65.

Devés, E. (2007). Redes intelectuales en América Latina. Santiago de Chile: IDEA-USACH.

Devés, E. (2008). La circulación de las ideas económicosociales de Latinoamérica y El Caribe, en Asia y África. ¿Cómo llegaron y cómo se diseminaron? (1965-1985). Universum, 2(23), 111-286.

Devés, E. (2009). Las ciencias económico-sociales latinoamericanas en África Sudhariana. Santiago de Chile: Adridna.

Ellenberger, H. F. (1970). The discovery of the unconscious. New York: Basic Books.

Escobar, E. (2002). Augusto Orrego Luco (18481933). Revista Chilena de Neuropsiquiatría, 40(1). doi: 10.4067/S0717-92272002000100010

Etchegoyen, H., \& Zysman, S. (2005). El psicoanálisis en América Latina. Una aproximación a la historia y las ideas. En S. Fechner \& S. Lewkoicz (Eds.), Verdad, realidad y el psicoanalista: contribuciones Latinoamericanas al psicoanálisis (pp. 1-23). Londres: Asociación Psicoanalítica Internacional.

Freud, S. (1972). Contribución a la historia del movimiento psicoanalítico. Obras Completas (L. López Ballesteros, Trad.). Madrid: Biblioteca Nueva. Vol. 2, pp. 981-1011.

Freud, S. (1991). G. Greve. Sobre psicología y psicoterapia de ciertos estados angustiosos. En E. Casaula, J. Coloma \& J. F. Jordan (Eds.), Cuarenta años de psicoanálisis en Chile. Santiago: Ananké. (Trabajo publicado en 1911)

García, G. (1980). La entrada del psicoanálisis en la Argentina. Buenos Aires: Catálogos. 
Gay, P. (1996). Freud. Una vida de nuestro tiempo. Buenos Aires: Paidós.

Gazmuri, C.; Zaldívar, M.I.; González, J.; Piña, J.; Machuca, G.; Mouesca, J. (2007). 100 años de cultura chilena (1905-2005). Santiago: Zig-Zag.

Gomberoff, M. (1990). Apuntes acerca de la historia del psicoanálisis en Chile. Revista de Psiquiatría, 7(1), 379-387.

Greve, G. (1895). La electricidad estática y sus aplicaciones en medicina. Revista Médica de Chile, 23(4-5), 176-220.

Greve, G. (1909, enero). Trabajos de la V Sección - Ciencias Médicas e Higiene. Cuarto Congreso Científico (1.. Pan-Americano). Santiago: Imprenta Barcelona.

Greve, G. (1910). Sobre psicología y psicoterapia de ciertos estados angustiosos. Santiago: Universo.

Greve Silva, G. (1969). Biografía de Don Germán Greve. Manuscrito no publicado.

Hale, N. (1995). Freud and the Americans. New York: Oxford.

Jones, E. (1997). Vida y obra de Sigmund Freud. Los años de madurez 1901-1919 (Vol. 2). Buenos Aires: Lumen-Horné .

McGrath, W. (1986). Freud's discovery of psychoanalysis. The politics of hysteria. Ithaca: Cornell University.

Huertas, R. (1987). Locura y degeneración. Madrid: Consejo Superior de Investigaciones Científicas, Departamento de Historia de la Ciencia.

León, R. (1982). Los psicoanalistas latinoamericanos y la difusión de sus trabajos en la Revista Internacional Zeitschrift für psychoanalyse: un estudio bibliomérico. Revista Latinoamericana de Psicología, 14(2), 171-182.

Makari, G. (2008). Revolution in mind. The creation of psychoanalysis. New York: Happer Prennial.

Molnar, M. (2011). Mysteries of nature. Psychoanalysis and History, 13, 39-67.

Molnar, M. (2010). Geheimnisse der Natur [Misterios de la Naturaleza]. Luzifer Amor, Heft 45 (23.Jg.2010).

Núñez, C. (1981). Fernando Allende Navarro (18901981). Revista Chilena de Psicoanálisis, 3(1-2), 4-7.

Olagaray, J. (1990). Significado de leer a Freud y el costado institucional de nuestra identidad. Cuadernos de Psicoanálisis, 23(3-4), 141-157.
Plotkin, M. (1996a). Freud en la Universidad de Buenos Aires: la primera etapa hasta la creación de la carrera de Psicología. Estudios Interdisciplinarios de América Latina y el Caribe, 7(1), 26-32.

Plotkin, M. (1996b). Freud y política: la recepción del psicoanálisis en Buenos Aires (1910-1943). Redes, 3(8), 163-198.

Plotkin, M. (2003). Freud en las pampas. Buenos Aires: Sudamericana .

Plotkin, M. (2009a). Psicoanálisis y habitus nacional: un enfoque comparativo de la recepción del psicoanálisis en Argentina y Brasil (1910-1950). Memoria y Sociedad, 13(27), 61-85.

Plotkin, M. (2009b). Psychoanalysis, transnationalism and national habitus: A comparative approach to the reception of psychoanalysis in Argentina and Brazil (1910s-1940s). En M. Plotkin \& J. Damousi (Eds.), Transnational unconscious. Essays in the history of psychoanalysis and transnationalism (pp. 145-178). Londres: Palgrave Macmillan.

Plotkin, M., \& Damousi, J. (Eds.). (2009). Transnational unconscious. Essays in the history of psychoanalysis and transnationalism. Londres: Palgrave-Macmillan.

Régis, E., \& Hesnard, A. (1914). La Psychanalyse des névroses et des psychoses. Ses applications médicales et extra-médicales. París: Félix Alcan.

Roa, A. (1974). Demonio y psiquiatría. Santiago: Andrés Bello.

Roa, A. (1980). Augusto Orrego Luco en la cultura y la medicina chilena. Santiago: Universitaria.

Roazen, P. (1994). Hermano animal. Buenos Aires: ACME Agalma.

Rosenthal, L. (1945). El psicoanálisis en la Argentina hace 35 años. Revista de Psicoanálisis, 3, 202-203.

Roudinesco, E. (1986). La batalla de los cien años: historia del psicoanálisis en Francia 1(1885-1939). Madrid: Fundamentos.

Ruperthuz, M. (2012). The 'Return of the Repressed': The role of sexuality in the reception of psychoanalysis in Chilean medical circles (1910s - 1940s). History $\mathscr{E}$ Psychoanalysis, 14(2), 285-296. doi: 10.3366/pah.2012.0113

Ruperthuz, M. (2013). Freud y los chilenos. Historia de la recepción del psicoanálisis en Chile (1910-1949) (Tesis para optar al Grado de Doctor en Psico- 


\section{Germán Greve Schlegel y la ReCepción del psicoanÁlisis en Chile: LA HISTORIA DE UN MÉDICO CHILENO "PROBABLEMENTE ALEMÁN"}

logía). Facultad de Ciencias Sociales, Escuela de Psicología, Universidad de Chile.

Russo, J. (2012). Brazilian psychiatrists and psychoanalysis at the beginning of the 20th century: A quest of national identity. Psychoanalysis $\mathbb{E}$ History, 14(2), 297-312.

Schorske, C. (1981). Fin-de-siècle Vienna. Politics and culture. New York: Vintage Books.

Saurí, J. (1984). Las histerias. Buenos Aires: Nueva Visión.

Vallejo, M. (abril, 2010). Reseña que escribió Freud acerca de la primera conferencia sobre teoría psicoanalítica en Argentina (1910). Revista Imago Agenda,
138. Recuperado de http://www.imagoagenda.com/ articulo.asp?idarticulo=1293

Vezetti, H. (1996). Freud en Buenos Aires (1910-1939). Buenos Aires: Universidad Nacional de Quilmes.

Whiting, C. (1980). Notas para la historia del psicoanálisis en Chile. Revista Chilena de Psicoanálisis, 2(1), 19-26.

The Wolfman. (1971). The wolf man. New York: Basic Books.

Zwettler-Otte, S. (2006). Freud and the Media. The reception of psychoanalysis in Viennese Medical Journal. Frankfurt: Peter Lang. 
